\title{
First detection of spring
}

\section{The spring edition of marketplace includes several aids for detection as well as software updates, cycle sequencing improvements and your choice of personal or fully automated workstations.}

\begin{tabular}{|c|}
\hline $\begin{array}{l}\text { For more } \\
\text { information call: }\end{array}$ \\
\hline $\begin{array}{l}\text { Amersham } \\
\text { International plc } \\
+44(0) 1494544000\end{array}$ \\
\hline $\begin{array}{l}\text { Autogen Bioclear } \\
\text { UK Ltd. } \\
\text { +44 (0) } 1380722635\end{array}$ \\
\hline $\begin{array}{l}\text { Bio Whittaker UK } \\
\text { Ltd. } \\
+44 \text { (0) } 1734795234\end{array}$ \\
\hline $\begin{array}{l}\text { Cherwell Scientific } \\
+44(0) 1865784800\end{array}$ \\
\hline $\begin{array}{l}\text { Cytocell Ltd. } \\
+44 \text { (0) } 1295810910\end{array}$ \\
\hline $\begin{array}{l}\text { Research Genetics } \\
+44(0) 800-89-1393 \\
\text { or } \\
1-800-533-4363\end{array}$ \\
\hline $\begin{array}{l}\text { Spectrotech } \\
+44 \text { (0) } 1223519028\end{array}$ \\
\hline $\begin{array}{l}\text { Tecan AG } \\
+4155418111\end{array}$ \\
\hline $\begin{array}{l}\text { Vysis } \\
1-708-271-7000\end{array}$ \\
\hline
\end{tabular}

A host of new methods for detecting everything from the obese gene product to specific DNA aberrations start off the spring biotechnology market report. Santa Cruz Biotechnology has developed two polyclonal antibodies to the obese $(\mathrm{Ob})$ gene product. A-20, raised against $\mathrm{C}$-terminal residues $137-156$, and $\mathrm{Y}-20$, against $\mathrm{N}$-terminal residues 16-34, react with human, mouse and rat leptin and can be used in immunoprecipitation, western blotting and immunohistochemistry. (These and other Santa Cruz products are available through its distributor Autogen Bioclear UK Ltd.)

Tumour biology studies become easier with the latest in a new family of cell markers from Bender MedSystems, distributed by Bio Whittaker. Seven highly specific and sensitive marker antibodies to $\mathrm{CD} 44$ variants detect a polymorphic family of cell surface proteins whose expression, on a variety of cell types, is associated with tumour progression. Antibodies can be used in western blot analysis, flow cytometry and immunohistochemistry.

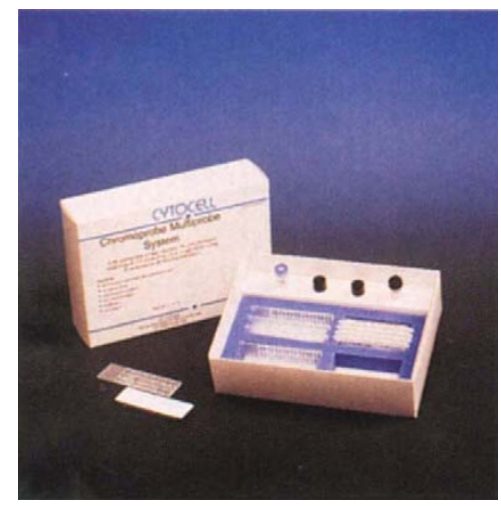

The Chromoprobe Multiprobe system for simultaneous 24-chromosome detection

Detecting genetic diseases involving chromosomal aberrations receives a boost through two new microdeletion assays, one for Prader-Willi syndrome and the other for Angelman syndrome from Vysis. The assays are based on Vysis' patented fluorescence in situ hybridization (FISH) technology. Probes for three separate loci enable detection of both unbalanced chromosome 15 translocations and de novo chromosomal deletions of SNRPN and D15S10 loci.

For further ease in cytogenetic studies, Cytocell Ltd. launches its new Chromoprobe Multiprobe System, a completely disposable system for detecting chromosomal aberrations in all 24 chromosomes simultaneously using FISH technology. The entire hybridization process takes place on a single microscope slide and requires only a heat denaturation step followed by standard washes for denaturation/hybridization. A new version of the Multiprobe containing 24 different centromeric probes will soon be available as well.

For DNA marker mapping, Research Genetics has a new radiation hybrid panel, Genebridge 4 . This panel consists of $85 \mathrm{RH}$ clones of the whole human genome. It can be used to order markers that are within 5,000 $\mathrm{kb}$ of each other and determine distance between them. This panel, adopted by the European Consortium on Radiation Hybrid Mapping, is a subset of the 199-clone panel from a collaboration between Peter Goodfellow's and Jean Wessenbach's labs. Investigators can order purified DNA from each of the 85 cell lines to map and order their own markers or use the Research Genetics service and have them do the mapping.

Once the markers are mapped and diseases detected, researchers will also have an easier time presenting and analysing data from familial genetic studies with Cherwell Scientific's release of its newest version of Cyrillic, pedigree drawing software. The new version 2.0 has enlarged colour support for haplotype bars, text annotation and new drawing tools and a multiple document interface allowing nine family-viewing simultaneously. As before, this version provides output for use in risk analysis programs and can read marker data files and provides DLL support for Paradox import and indexing.

Gene sequencing also gets simpler as Amersham Life Science, following up on the launch of its newest sequencing enzyme Thermo Sequenase $^{\mathrm{TM}}$, presents Thermo Sequenase cycle sequencing kits, which provide even band intensities. Two kits are available: one for use with $\left[{ }^{32} \mathrm{P}\right]$, $\left[{ }^{33} \mathrm{P}\right]$ or $\left[{ }^{35} \mathrm{~S}\right]$, the other for fluorescent cycle sequencing. Amersham also offers Complete Thermo Sequenase kits designed for use in the Vistra Labstation 625, making it possible to completely automate the procedure from template preparation to excess dye terminator removal.

Speaking of automation, Tecan AG now has the Genesis RMP, which allows fully automated Robotic Microplate processing. The Genesis RMP is an upgrade of the Genesis RSP series. The complete system

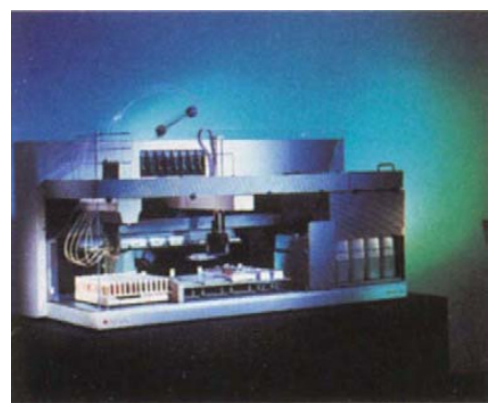

The fully automated Genesis RMP

includes the Robotic Manipulator (RoMa) arm, room temperature or heated incubation, an optional shaking unit, an SLT Columbus microplate washer and an SLT Spectra microplate reader. The system can do up to 12 different tests on 6 microplates, the processes are controlled by Windows NT-based software that can interface with conventional laboratory information systems. All in all it offers true userindependent operation.

For those DNA analyses where more personal attention is required, Spectrotech now has a personal DNA workstation. The Spectrotech DNA Workstation $(470 \times 300 \mathrm{~mm})$ is particularly suited for researchers using PCR technology as it allows each individual researcher his/her own workspace for handling, without cross contamination, nucleic acids, cell cultures and other biological samples. The workstation uniquely combines a UV sterilized workspace with HEPA-filtration and activated carbon, providing both a germ-free and vapour-controlled environment.

Notes compiled by Laurie Goodman. 